\title{
Social cognition in individuals with 22q11.2 deletion syndrome and its link with psychopathology and social outcomes: a review
}

Branka Milic $^{1^{*}}$ (D), Clémence Feller ${ }^{2}$, Maude Schneider ${ }^{2}$, Martin Debbané $e^{3,4}$ and Henriette Loeffler-Stastka ${ }^{1}$

\begin{abstract}
Background: The 22q11.2 deletion syndrome (22q11DS) is a genetic syndrome that results in a highly variable profile of affected individuals of which impairments in the social domain and increased psychopathology are the most prominent. Notably, 25-30\% of affected individuals eventually develop schizophrenia/psychosis, predisposing persons with the syndrome to increased risk for this disorder. Because social cognition is considered to underlie social behavior and to be related to psychopathology, this systematic review investigated social cognition in individuals with 22q11DS and examined reported links across its domains with psychopathology and social outcomes. This can provide the basis for a closer understanding of the path from risk to disorder and will inform on the specific domains that can be targeted with preventive intervention strategies.
\end{abstract}

Method: Systematic literature review of studies that reported the links between social cognitive domains and psychopathology and/or social outcomes in individuals with 22q11DS. Electronic databases searched were PubMed and PsycINFO.

Results: Defined eligibility criteria identified a total of ten studies to be included in the present review. Selected studies investigated links between two domains of social cognition (emotion processing and theory of mind (ToM)) and psychopathology and/or social outcomes. With respect to the links to psychopathology, two aspects of social cognition were related primarily to negative symptoms. Results regarding the associations to positive and emotional symptoms (anxiety/depression) are limited and require further investigation. Even though both aspects of social cognition were associated with social outcomes, several studies also found no links between these two domains. Both reports invite for an additional examination of reported results and specific considerations regarding chosen constructs.

Conclusion: Although equivocal, results of the present review provide sufficient evidence that social cognition is a useful domain for the closer elucidation of clinical outcomes and social difficulties in this population. At the same time, longitudinal studies and consideration of other variables are also necessary for a timely understanding of affected persons in this respect.

Keywords: 22q11DS, Social cognition, Emotion processing, Theory of mind, ToM, Mentalizing, Psychopathology, Schizophrenia, Psychosis, Social outcomes, Preventive interventions

\footnotetext{
* Correspondence: branka-milic@hotmail.com

${ }^{1}$ Clinic for Psychoanalysis and Psychotherapy, Medical University of Vienna, Vienna, Austria

Full list of author information is available at the end of the article
}

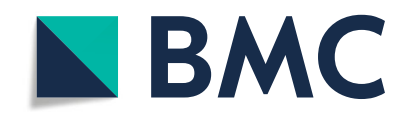

(c) The Author(s). 2021 Open Access This article is licensed under a Creative Commons Attribution 4.0 International License, which permits use, sharing, adaptation, distribution and reproduction in any medium or format, as long as you give appropriate credit to the original author(s) and the source, provide a link to the Creative Commons licence, and indicate if changes were made. The images or other third party material in this article are included in the article's Creative Commons licence, unless indicated otherwise in a credit line to the material. If material is not included in the article's Creative Commons licence and your intended use is not permitted by statutory regulation or exceeds the permitted use, you will need to obtain permission directly from the copyright holder. To view a copy of this licence, visit http://creativecommons.org/licenses/by/4.0/. The Creative Commons Public Domain Dedication waiver (http://creativecommons.org/publicdomain/zero/1.0/) applies to the data made available in this article, unless otherwise stated in a credit line to the data. 


\section{Background}

The 22q11.2 deletion syndrome (22q11DS) is a genetic syndrome associated with a microdeletion on the long arm of chromosome 22, which is appointed as 22q11.2 deletion [1]. Commonly, 22q11 deletion comprises about 50 genes, with a reported prevalence of 1 in every 2000 [2], $4000[2,3]$ to 6000 [4] births, and in over $90 \%$ of the cases is de novo [5]. Given that $25-30 \%$ of affected individuals eventually develop schizophrenia/psychosis, 22q11DS is acknowledged as the second-highest genetic risk factor for the development of schizophrenia. Additionally, since the phenotypic expression of schizophrenia in 22q11DS is indistinguishable from idiopathic schizophrenia, a closer understanding of affected individuals provides an opportunity for elucidating the trajectory path from risk to disorder [6]. Equally, this can serve as a basis for preventive and intervention strategies designed to ameliorate behavioral and functional challenges encountered by affected persons and their environment.

Even though 22q11DS is known for its inter- and intra-individual phenotypic variability [7], domains that are regularly affected involve cognitive, psychiatric, and social domain. Individuals with 22q11DS often face impairments in neurocognition (working memory, executive function, borderline (IQ, 70-84) to mild (IQ < 70) intellectual disability) and social cognition [8]. Interestingly, cognitive abilities (verbal and performance IQ) are found to be inversely associated with age in this population and more severe intellectual disability is encountered mainly in adults [9-11]. Concerning psychiatric characteristics, behavioral issues are the most common reported symptoms [11] and are often classified under general or emotional symptoms (e.g., depression, anxiety, tension, poor impulse control), negative symptoms (e.g., social anhedonia or withdrawal, avolition, difficulty in abstract thinking), and positive symptoms (e.g., unusual perceptual experiences, delusions, hallucinations) (e.g., $[12,13])$. Therefore, diagnostic categories frequently associated with the syndrome involve attention deficit hyperactivity disorder (ADHD), autism spectrum disorders (ASD), anxiety, mood disorders (major depression), and psychosis. Notably, the prevalence of the specific psychiatric categories is also related to the age of affected individuals [8]. Thus, certain diagnostic categories are most frequently encountered in children and adolescents (ADHD, ASD), anxiety can be found in all age groups, and the prevalence of major depression and schizophrenia/psychosis significantly increases with the age of affected individuals [8].

Reports on the social domain are divided. Many studies suggest this domain to be affected, since children with the syndrome are described as being socially immature, withdrawn, shy, and as facing challenges in initiating and forming lasting social relationships (e.g., [14,
15]). By contrast, early studies with very young children confirm no such findings $[16,17]$. Nevertheless, the developmental trajectory of behavior in affected individuals tends to shift from an externalizing profile (attention deficit, oppositional, impulsive) encountered at a younger age to an internalizing profile (withdrawn, shy, lack of initiative) that is characteristic for individuals with 22q11DS in adolescence and adulthood [11].

\section{Social cognition, psychopathology and social outcomes in individuals with 22q11DS}

A large number of studies on individuals across the psychosis spectrum (e.g., patients with schizophrenia [18], young people at clinical high risk for psychosis [19], and the population with 22q11DS (e.g., [20, 21])) have reported impairments in the social area. Given that social cognition is considered to underlie social behavior [22] and can serve as a potential marker for schizophrenia and other clinical conditions [23], this specific domain has received considerable attention in research on schizophrenia and 22q11DS.

According to The Social Cognition Psychometric Evaluation (SCOPE) study, there are four major domains of social cognition: emotion processing, theory of mind (ToM), social perception, and attributional style/bias [24]. Emotion processing, also referred to as the "socialperceptual" (affective) aspect of social cognition, refers to the way a person perceives, attends to, and recognizes other people with the ability of a person to correctly detect facial emotions [22]. This domain of social cognition has been extensively researched in 22q11DS and impairments in face memory, face recognition, and emotion identification have been reported in individuals with the syndrome (e.g., [25-29]). Theory of mind (mental state attribution), also referred to as "social-cognitive" (reflective) aspect of social cognition, denotes the ability of an individual to understand that other people have mental states (thoughts, beliefs, intentions) independent and different from one's own and to make attributions about the mental states of others [30]. This includes understanding false-beliefs, hints, intentions, deception, irony, metaphor, and faux pas [18]. Although studies tend to report deficits in ToM in individuals with 22q11DS (e.g., $[21,26])$, worthy of note is the impact of age, since in typical development, this domain continues to improve during adolescence and early adulthood [31]. Social perception (or social knowledge) refers to the individual's ability to decode and interpret social roles, social rules, and contexts from non-verbal cues (i.e., body language, voice intonation) [32]. Attributional style/bias depicts how persons tend to explain the causes of social interactions and events [33]. To the best of our knowledge, social perception and attributional style/bias have received little or no attention in the field of 22q11DS at this 
stage. It is significant to note that even though four identified domains of social cognition are described as distinct processes, they are not completely separate. Rather, these constructs interact and require the integration of complex skills for a person to attain socially adaptive behavior [34]. In this respect, social outcomes are often operationalized through assessments of social skills, competence, and/or functioning. Specifically, social skills or competencies denote the behaviors necessary for a person to be engaged in successful interpersonal interactions; social functioning is associated with everyday domains, such as independent living, employment, interpersonal relationships [35, 36].

Interconnection of previously defined concepts and their link with psychopathology has been a topic of extensive research and discussion in the field. By way of example, social cognitive deficits have been consistently confirmed in individuals with schizophrenia and psychosis in all phases of illness $[19,37,38]$. Specific associations have been reported between social cognition and negative symptoms of psychosis in persons with schizophrenia [18]. Similarly, Chow et al. found that individuals with 22q11DS who developed psychosis displayed more severe ToM impairments compared to those who did not develop psychosis [20]. However, it should be noted that deficits in social cognition have been reported in 22q11DS regardless of psychopathology status [39] and even in the absence of a psychotic disorder [40].

Concerning the association between social cognition and social outcomes, findings seem to be divided. Indeed, a meta-analysis on individuals with schizophrenia reported medium to large associations between social cognition and functioning [41] that also proved to be stable over time [32, 42, 43]. Specifically, a deficit in emotion perception and social-cognitive problem-solving in persons with schizophrenia were associated with social competence. Similarly, emotion processing had a consistent relationship with social functioning $[44,45]$ and ToM was predictive of social skills in individuals with schizophrenia [46]. At the same time, however, several studies reported no significant association between a combined measure of social cognition (emotion processing and ToM) [47] or specifically between ToM [48] and social outcomes in persons with psychosis. In a similar manner, research on these specific associations in persons with 22q11DS has also shown inconsistent results. For instance, Vangkilde at al. examined both aspects of social cognition and found no significant association with social competence, skills, and functioning [49]. In contrast, Campbell et al. reported associations between both domains of social cognition and social outcomes [50].

Even though deficits in social cognition could partly account for social dysfunction and are often related to psychopathology in individuals with 22q11DS, reported evidence that links specific social cognitive domains to clinical and social outcomes has been ambiguous and often contradictory. Therefore, the present paper aims to gather and systematically review studies conducted on individuals with 22q11DS that have examined and reported associations between any domain of social cognition and psychopathology and/or social outcomes. In order to achieve this goal, we will first: systematically select studies on individuals with 22q11DS and social cognition. Second, we will look for the studies that have also assessed psychopathology and social outcomes in affected persons. Third, we will extract the data that reported associations between social cognition and psychopathology and/or social outcomes. Fourth, we will provide a narrative synthesis and interpretation of the reported information and will aim to highlight critical aspects of the current state of research on the topic including plausible clinical implications. This could serve as the basis for future research in the field that can lead to informed decisions on early prevention and management of behavioral and clinical difficulties in 22q11DS and will possibly benefit clinicians involved in their work with this population.

\section{Method}

\section{Search strategy}

Following the Preferred Reporting Items for Systematic Reviews and Metanalysis (PRISMA) [51], a systematic search was conducted using two electronic databases PubMed and PsycINFO until April 29th, 2020. The search terms for 22q11 deletion syndrome (DS) were based on keywords and phrases encountered in the literature related to the syndrome including early publications. The following search terms for 22q11DS involved: "22q11 deletion syndrome," "22q11," "velocardiofacial syndrome," "DiGeorge Syndrome," "CATCH-22," "Shprintzen syndrome," and were combined with OR. Social cognitive domains are defined by the SCOPE study [24] and include: emotion processing, social perception, theory of mind, and attributional style/bias; thus, search terms for this domain were: "social cognition," "theory of mind," "social perception," "facial identification," "face recognition," "face memory," "emotion perception," "affect recognition," "emotion processing," "attributional bias," and were combined by OR. The final result for the search string regarding 22q11 DS was combined with the final result for the search string regarding social cognition with AND.

Domains related to psychopathology and social outcomes were not part of the search strategy, as the aim was to gather all publications on social cognition in 22q11DS and to manually select studies that fitted eligibility criteria. Reference lists and studies from other sources were also searched for possible relevant articles. 


\section{Eligibility criteria}

Papers were eligible to be included in the review if they met the following inclusion criteria: 1) research involving participants with a confirmed 22q11.2 deletion syndrome, 2) at least one task assessing social cognition, 3) at least one assessment of psychopathology and social outcomes, 4) reported associations between social cognition in individuals with 22q11DS and psychopathology and/or social outcomes. Papers were excluded if they: did not meet these criteria, were case studies, were studies reporting results of interventions, and if they were not empirical studies (e.g., review papers, expert opinions, published theses).

\section{Study selection}

The first author conducted the search in electronic databases PubMed and PsycINFO. A selection of the studies was then independently done by two authors (BM, CF), thereafter compared, and an agreement for the final inclusion of the studies was reached. The search strategy resulted in a total of 219 retrieved studies. After $41 \mathrm{du}-$ plicates were removed, 178 studies were screened based on the titles and abstracts; two studies were added from other sources. In total, sixty-six articles were screened for eligibility criteria based on the full-texts. Twenty-two studies included all four domains of interest. Twelve studies were then excluded, as they have not investigated nor reported associations between social cognition and either psychopathology or social outcomes. The selection process is presented in the methodological flowchart (Fig. 1).

\section{Results}

\section{Study characteristics}

Defined eligibility criteria identified a total of ten studies to be included in the present review (Table 1). The age of participants in the selected studies was between 6 and 33 years old. Five papers involved sample sizes with 24 to 35 participants $[49,54-57]$; five articles had more than 40 participants [50, 52, 53, 58, 59]. Two articles had longitudinal designs $[58,59]$ and one study was conducted at two sites (UCLA, SUNY) [52]. A complete overview of included studies, with main characteristics and assessments for each domain is presented in Table 1.

Included articles addressed three previously defined domains of social cognition: emotion processing (socialperceptual part), ToM (social-cognitive part), and social perception; no study investigated attributional style/bias. Specifically, nine studies assessed emotion processing (social-perceptual aspect) [49, 50, 53-59], five papers examined social-cognitive part (ToM) [49, 50, 52, 54, 55], and one article investigated social perception [57]; four studies involved assessments of (both) social-perceptual and social-cognitive aspects of social cognition [49, 50, 54, 55]. Descriptions of the tasks used to assess social cognition (emotion processing, ToM, and social perception) in the included papers are presented in the Additional file 1.

All nine studies that assessed emotion processing (social-perceptual part) reported deficits in individuals with 22q11DS. The only study that found no significant difference between individuals with 22q11DS and the control group in emotion recognition used a different form of assessment (by the tone of voice) [53], compared to the remaining studies that examined the recognition of facial expressions.

Findings on the assessment of ToM (social-cognitive part) were not as consistent. Although all five studies that evaluated this aspect of social cognition reported deficits in individuals with 22q11DS [49, 50, 52, 54, 55], some acknowledged no difference with the control group in response times $[54,55]$ or for simpler (firstorder) stories/tasks [50].

The only study that assessed social perception in individuals with 22q11DS [57] found reduced brain activation in regions belonging to the default mode network (DMN) (except for temporal lobes) during the perception of social information compared to controls. However, the betweengroup comparison of social perception did not reveal any significant difference between the two groups. The same result was found for the influence of emotions on social perception (in within- and between-group comparisons) [57].

Concerning psychopathology and social outcomes, all included studies reported elevated symptoms (general, negative, positive) and poorer social outcomes in individuals with 22q11DS. One article reported similar results between the groups on cognitive-perceptual (unusual perceptual experiences, paranoid ideation) and disorganised dimension (odd behavior and speech) of schizotypy [55]; additionally, one paper found no differences in prosocial behavior [54]. Assessments of psychopathology and social outcomes are listed in Table 1 and Additional file 1.

\section{Links between social cognitive domains and psychopathology and/or social outcomes}

Identified studies reported associations between two domains of social cognition - emotion processing (socialperceptual part) and theory of mind (social-cognitive part) - and psychopathology and/or social outcomes. An overview of the reported links between social cognition and the domains of interest is presented in Table 2.

\section{Emotion processing - social-perceptual (affective) part}

In total, five papers reported associations between social-perceptual aspects of social cognition and psychopathology. Four of these studies found significant associations between face and emotion recognition and 


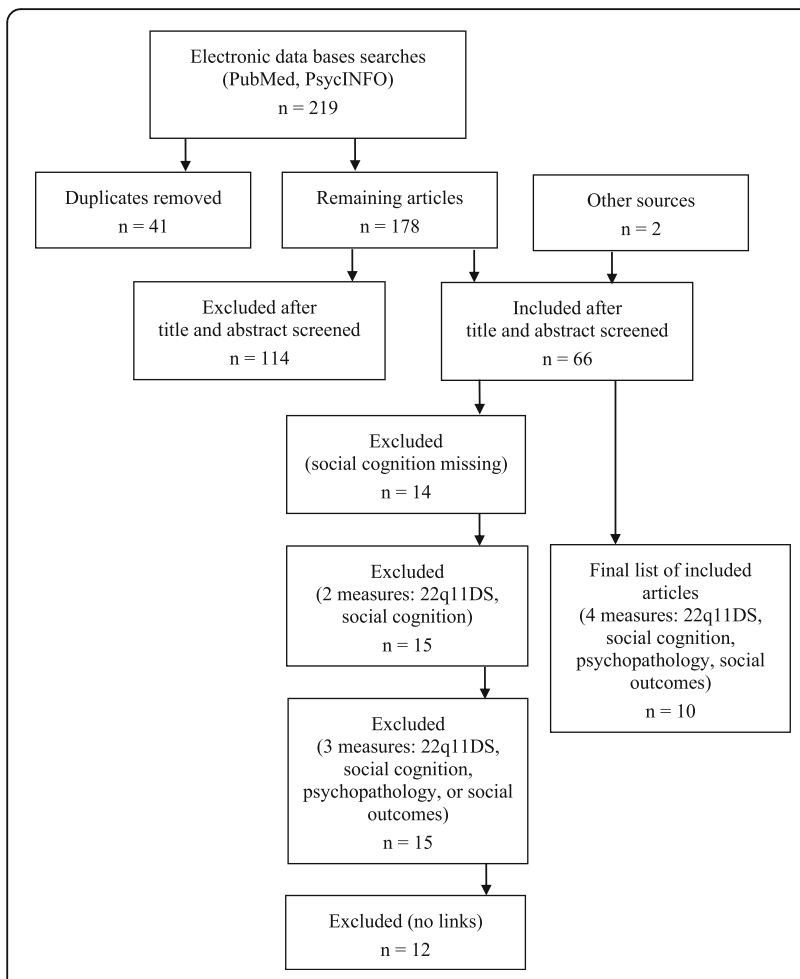

Fig. 1 Methodological Flowchart

negative symptoms $[49,56,58]$ and paranoid schizotypal symptoms [56]. No association was found between this aspect of social cognition (specifically, face discrimination) and internalizing, anxious/depressive traits [58].

In the domain of social outcomes, three papers reported significant associations with social cognition. Specifically, emotion processing was associated with peer relationship problems $[50,54]$ and with the severity of negative performance beliefs [56]. In contrast, four studies found no significant association between the socialperceptual aspect of social cognition and any social outcome (Table 2).

\section{Theory of mind (ToM) - social-cognitive (reflective) part}

Three papers reported specific associations between this aspect of social cognition and psychopathology. Associations were reported with the severity of negative symptoms $[49,55]$ as well as disorganised traits (odd behavior and speech) [55]. One study reported that upon removing participants who were on antipsychotic medication, previously marginal associations to positive, negative, and disorganisation schizotypal traits became significant [55]. No associations were found between this aspect of social cognition and attenuated positive symptoms of psychosis $[49,52]$.

Concerning social outcomes, reports are divided: two studies found associations to peer relationship problems $[50,52]$, while three papers found no associations to any of the social outcome measures $[49,54,55]$. Studies with confirmed links between the social-cognitive part of social cognition and social outcomes included larger samples $(n>50)$ (Table 2).

\section{Links between social cognitive domains and other variables}

Six studies presented the impact of other variables (age, IQ, working memory (WM), executive function (EF)) on social cognition in individuals with 22q11DS (Table 3). Both aspects of social cognition were mainly associated with age. Zaharia et al. pointed that accuracy on configural different $(\mathrm{CD})$ trials (comparing original face photo to the versions of face photos with eyes/mouth being moved up, down, further or closer) significantly increased with age only in typically developing participants compared to the affected individuals [58]. Most studies found no link to IQ. Emotion processing was related to WM and grammar reception [50]; ToM was associated with EF [54] and grammar reception [50] - each aspect of social cognition by a single study (Table 3 ). Assessments of neurocognition and social cognition are presented in the Additional file 1.

\section{Discussion}

We systematically reviewed studies that investigated the links between social cognitive domains and psychopathology and/or social outcomes in individuals with 22q11DS. Additionally, we included reported links between social cognition and other (neurocognitive) variables or age. Results can be summarized in the following points: 1) Ten identified studies involved assessments of three aspects of social cognition: emotion processing (social-perceptual (affective) part), ToM (social-cognitive (reflective) part), social perception and reported associations between two aspects of social cognition (emotion processing and ToM) and psychopathology and/or social outcomes. 2) With respect to psychopathology, associations were confirmed mainly with the severity of negative symptoms of psychosis. Concerning the relationship with positive symptoms of psychosis or emotional symptoms (anxiety/depression), the current state of research in the field of 22q11DS is limited and equivocal. 3) Results regarding the links between social cognitive domains and social outcomes are inconsistent. 4) Most studies point to an impact of age on social cognitive domains. Results will be discussed in the context of the existing body of knowledge on 22q11DS and schizophrenia research. Finally, clinical implications with preventive and treatment propositions will be considered.

\section{Social cognition in individuals with 22q11DS}

Almost all included studies reported deficits in the assessed domains of social cognition. With respect to 


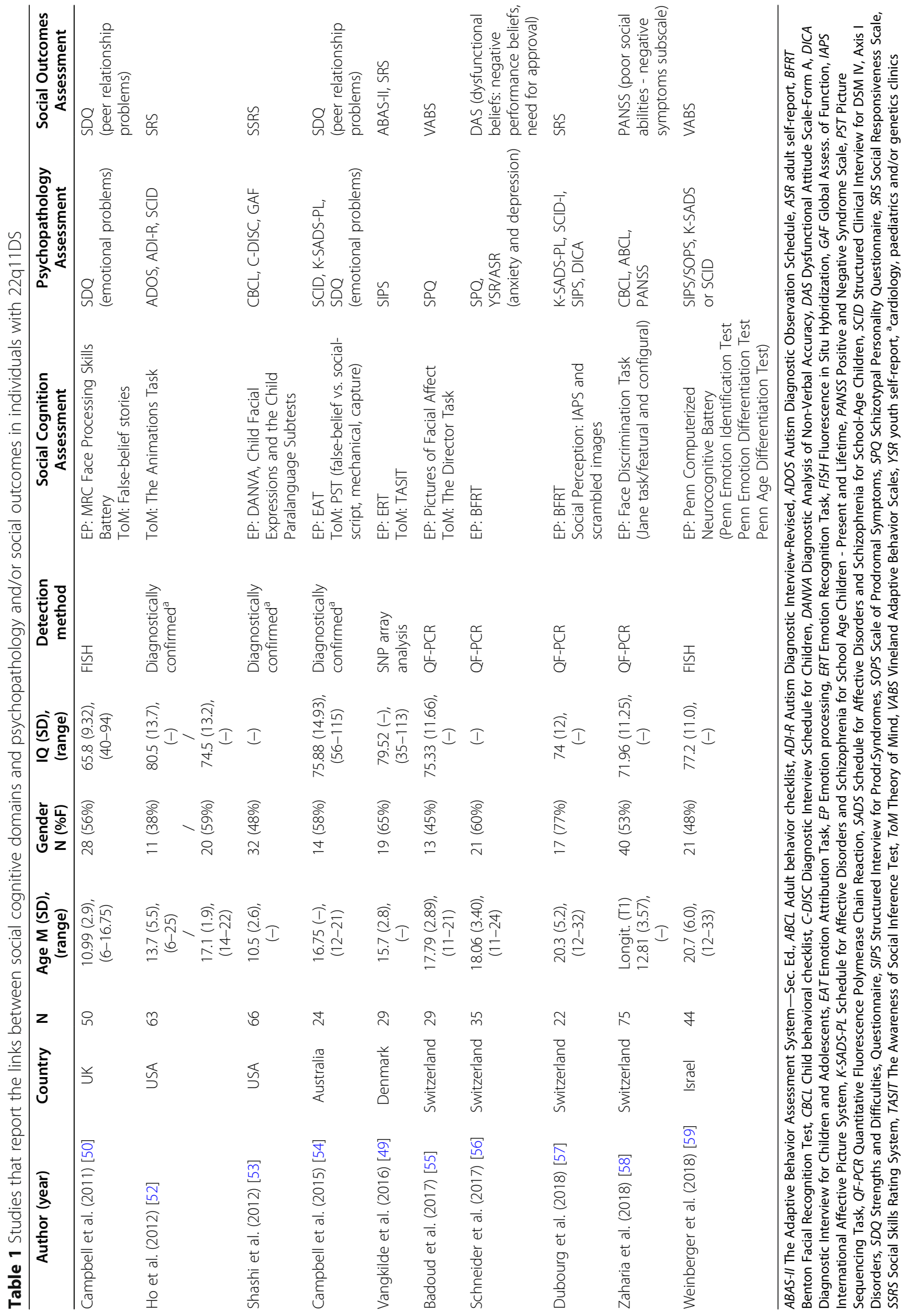




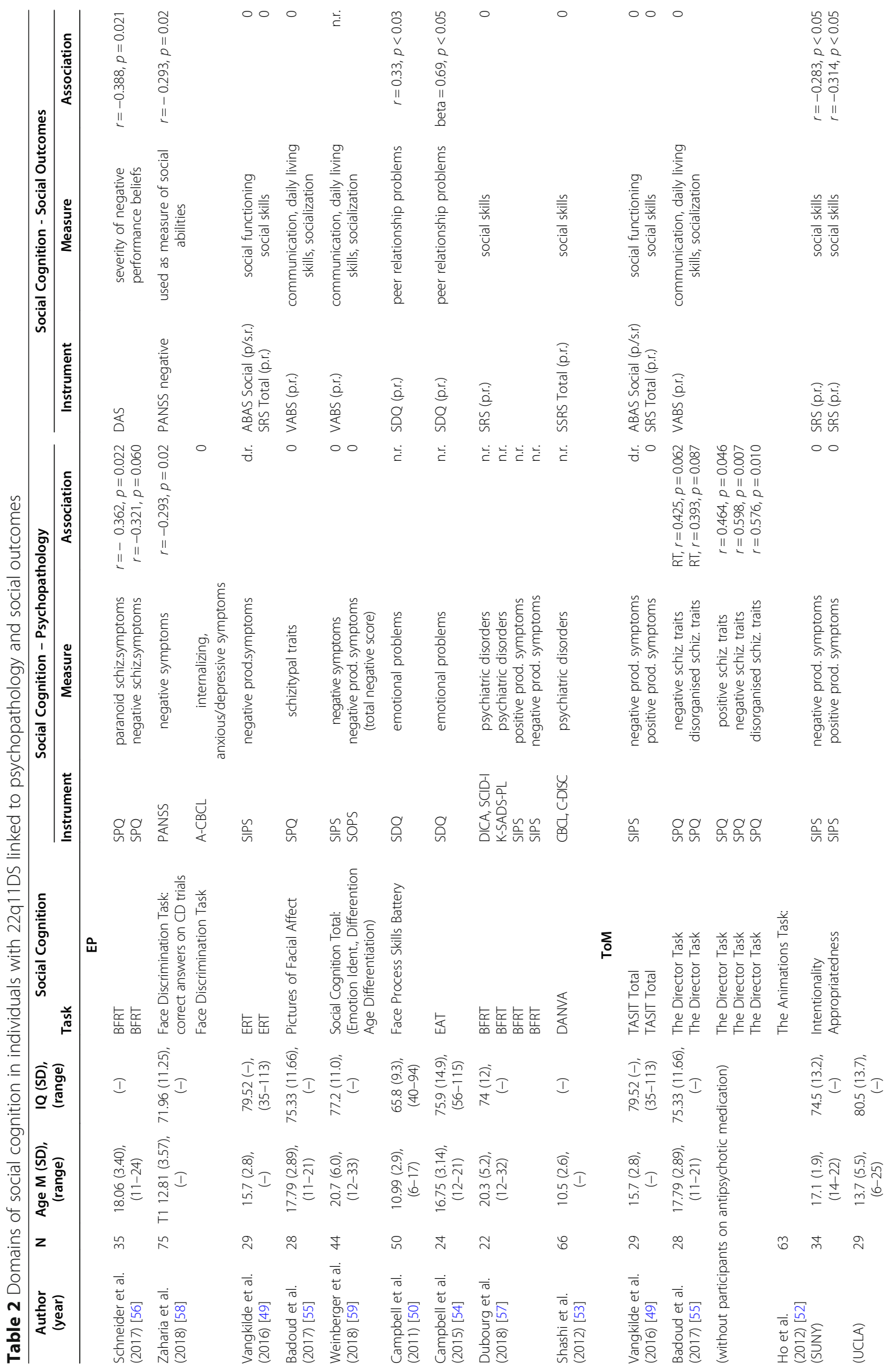




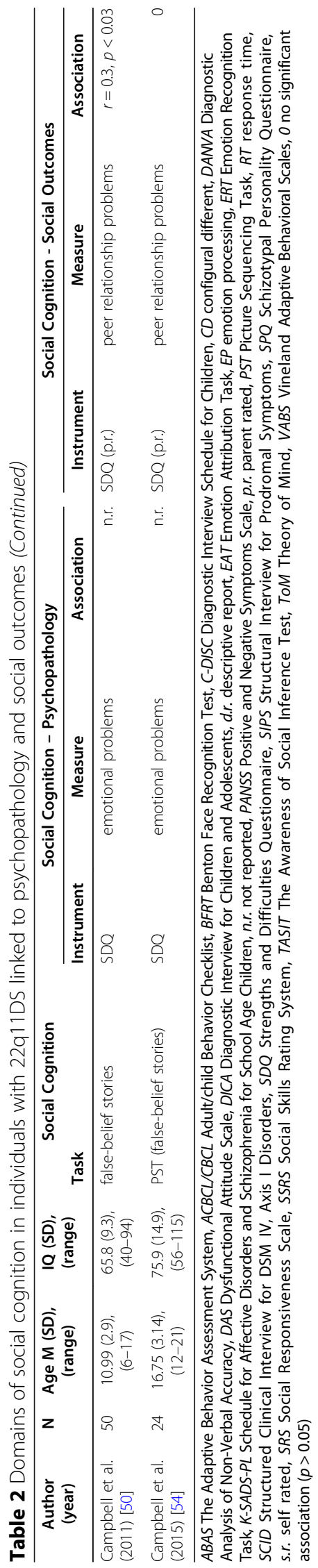


Table 3 Domains of social cognition in individuals with 22q11DS linked to other variables

\begin{tabular}{|c|c|c|c|c|c|c|}
\hline \multicolumn{7}{|c|}{ Social Cognition } \\
\hline Author & $\mathrm{N}$ & $\begin{array}{c}\text { Age M (SD), } \\
\text { (range) }\end{array}$ & $\begin{array}{l}\text { IQ (SD), } \\
\text { (range) }\end{array}$ & Task & Variable & Association \\
\hline & & & & EP & & \\
\hline $\begin{array}{l}\text { Vangkilde et al. } \\
\text { (2016) [49] }\end{array}$ & 29 & $\begin{array}{c}15.7(2.8), \\
(-)\end{array}$ & $\begin{array}{l}79.52(-), \\
(35-113)\end{array}$ & ERT & QQ & $r=0.43, p=0.02$ \\
\hline $\begin{array}{l}\text { Zaharia et al. } \\
\text { (2018) [58] }\end{array}$ & 75 & $\begin{array}{c}\text { T1 12.81 (3.57), } \\
(-)\end{array}$ & $\begin{array}{c}71.96(11.25), \\
(-)\end{array}$ & Face Discrimination Task & IQ & 0 \\
\hline $\begin{array}{l}\text { Shashi et al. } \\
\text { (2012) [53] }\end{array}$ & 66 & $\begin{array}{c}10.5(2.6), \\
(-)\end{array}$ & $(-)$ & DANVA & QQ & 0 \\
\hline $\begin{array}{l}\text { Badoud et al. } \\
\text { (2017) [55] }\end{array}$ & 29 & $\begin{array}{c}17.79(2.89) \\
(11-21)\end{array}$ & $\begin{array}{c}75.33(11.66), \\
(-)\end{array}$ & Pictures of Facial Affect & QQ & 0 \\
\hline $\begin{array}{l}\text { Vangkilde et al. } \\
\text { (2016) [49] }\end{array}$ & 29 & $\begin{array}{c}15.7(2.8), \\
(-)\end{array}$ & $\begin{array}{l}79.52(-), \\
(35-113)\end{array}$ & ERT & age & $\mathrm{F}=10.58, p=0.002$ \\
\hline \multirow[t]{4}{*}{$\begin{array}{l}\text { Campbell et al. } \\
\text { (2011) [50] }\end{array}$} & 50 & $\begin{array}{c}10.99(2.9), \\
(6-17)\end{array}$ & $\begin{array}{l}65.8(9.3), \\
(40-94)\end{array}$ & Face Process Skills Battery & & \\
\hline & & & & Identity & age & beta $=0.235, p<0.005$ \\
\hline & & & & Gaze & age & beta $=0.226, p<0.02$ \\
\hline & & & & Facial speech & age & beta $=0.242, p<0.03$ \\
\hline $\begin{array}{l}\text { Zaharia et al. } \\
\text { (2018) [58] }\end{array}$ & 75 & T1 $12.81(3.57)$, & $\begin{array}{c}71.96(11.25), \\
(-)\end{array}$ & Face Discrimination Task & age & d.r. \\
\hline $\begin{array}{l}\text { Badoud et al. } \\
\text { (2017) [55] }\end{array}$ & 29 & $\begin{array}{c}17.79(2.89) \\
\quad(11-21)\end{array}$ & $\begin{array}{c}75.33(11.66), \\
(-)\end{array}$ & Picturres of Facial Affect & age & 0 \\
\hline $\begin{array}{l}\text { Campbell et al. } \\
\text { (2011) [50] }\end{array}$ & 50 & $\begin{array}{c}10.99(2.9), \\
(6-17)\end{array}$ & $\begin{array}{l}65.8(9.3), \\
(40-94)\end{array}$ & Face Process Skills Battery & WM & $r=0.44, p<0.001$ \\
\hline $\begin{array}{l}\text { Campbell et al. } \\
\text { (2011) [50] }\end{array}$ & 50 & $\frac{10.99(2.9),}{(6-17)}$ & $\begin{array}{l}65.8(9.3), \\
(40-94)\end{array}$ & Face Process Skills Battery & grammar reception & $r=0.646, p<0.0005$ \\
\hline $\begin{array}{l}\text { Shashi et al. } \\
\text { (2012) [53] }\end{array}$ & 66 & $\begin{array}{c}10.5(2.6), \\
(-)\end{array}$ & $(-)$ & DANVA & EF & 0 \\
\hline $\begin{array}{l}\text { Shashi et al. } \\
\text { (2012) [53] }\end{array}$ & 66 & $\begin{array}{c}10.5(2.6) \\
(-)\end{array}$ & $(-)$ & DANVA & $\begin{array}{l}\text { verbal learning and } \\
\text { memory }\end{array}$ & 0 \\
\hline \multirow[t]{2}{*}{$\begin{array}{l}\text { Shashi et al. } \\
\text { (2012) [53] }\end{array}$} & 66 & $\begin{array}{c}10.5(2.6), \\
(-)\end{array}$ & $(-)$ & DANVA & sustained attention & 0 \\
\hline & & & & ToM & & \\
\hline \multirow[t]{4}{*}{$\begin{array}{l}\text { Ho et al. (2012) } \\
\text { [52] }\end{array}$} & 34 & $\begin{array}{l}17.1(1.9), \\
(14-22)\end{array}$ & $\begin{array}{c}74.5(13.2), \\
(-)\end{array}$ & The Animations Task: & & \\
\hline & & & & Intentionality (SUNY) & IQ & $r=0.511, p<0.01$ \\
\hline & & & & Appropriatedness (SUNY) & IQ & $r=0.463, p<0.01$ \\
\hline & & & & Appropriatedness (random) & IQ & $r=0.453, p<0.01$ \\
\hline \multirow[t]{3}{*}{$\begin{array}{l}\text { Ho et al. (2012) } \\
\text { [52] }\end{array}$} & 29 & $\begin{array}{c}13.7(5.5), \\
(6-25)\end{array}$ & $\begin{array}{c}80.5(13.7), \\
(-)\end{array}$ & The Animations Task: & & \\
\hline & & & & Intentionality (UCLA) & IQ & 0 \\
\hline & & & & Appropriatedness (UCLA) & IQ & 0 \\
\hline $\begin{array}{l}\text { Vangkilde et al. } \\
\text { (2016) [49] }\end{array}$ & 29 & $\begin{array}{c}15.7(2.8), \\
(-)\end{array}$ & $\begin{array}{l}79.52(-), \\
(35-113)\end{array}$ & TASIT & QQ & 0 \\
\hline $\begin{array}{l}\text { Badoud et al. } \\
\text { (2017) [55] }\end{array}$ & 29 & $\begin{array}{c}17.79(2.89), \\
(11-21)\end{array}$ & $\begin{array}{c}75.33(11.66), \\
(-)\end{array}$ & The Director Task & IQ & 0 \\
\hline $\begin{array}{l}\text { Campbell et al. } \\
\text { (2011) [50] }\end{array}$ & 50 & $\begin{array}{c}10.99(2.9), \\
(6-17)\end{array}$ & $\begin{array}{l}65.8(9.3), \\
(40-94)\end{array}$ & False-belief stories & age & $r=0.61, p<0.0005$ \\
\hline $\begin{array}{l}\text { Vangkilde et al. } \\
\text { (2016) [49] }\end{array}$ & 29 & $\begin{array}{c}15.7(2.8), \\
(-)\end{array}$ & $\begin{array}{l}79.52(-), \\
(35-113)\end{array}$ & TASIT & age & $r=0.35, p=0.07$ \\
\hline $\begin{array}{l}\text { Ho et al. } \\
\text { (2012) [52] }\end{array}$ & 63 & & & The Animations Task: & & \\
\hline (SUNY) & 34 & $\begin{array}{l}17.1(1.9), \\
(14-22)\end{array}$ & $\begin{array}{c}74.5(13.2), \\
(-)\end{array}$ & Intentionality (SUNY, UCLA) & age & 0 \\
\hline (UCLA) & 29 & $\begin{array}{c}13.7(5.5), \\
(6-25)\end{array}$ & $\begin{array}{c}80.5(13.7), \\
(-)\end{array}$ & Appropriatedness (SUNY, UCLA) & age & 0 \\
\hline $\begin{array}{l}\text { Badoud et al. } \\
\text { (2017) [55] }\end{array}$ & 29 & $\begin{array}{c}17.79(2.89) \\
\quad(11-21)\end{array}$ & $\begin{array}{c}75.33(11.66), \\
(-)\end{array}$ & The Director Task & age & 0 \\
\hline $\begin{array}{l}\text { Campbell et al. } \\
\text { (2015) [54] }\end{array}$ & 24 & $\begin{array}{c}16.75(3.14) \\
(12-21)\end{array}$ & $\begin{array}{l}75.9(14.9), \\
(56-115)\end{array}$ & PST (false-belief stories) & EF & beta $=0.44, p<0.01$ \\
\hline $\begin{array}{l}\text { Campbell et al. } \\
\text { (2011) [50] }\end{array}$ & 50 & $\begin{array}{c}10.99(2.9), \\
(6-17)\end{array}$ & $\begin{array}{l}65.8(9.3), \\
(40-94)\end{array}$ & False belief-stories & grammar reception & $r=0.347, p<0.015$ \\
\hline
\end{tabular}

DANVA Diagnostic Analysis of Non-Verbal Accuracy, d.r. descriptive report, EAT Emotion Attribution Task, EF executive function, EP emotion processing, ERT Emotion Recognition Task, FERT Facial Emotion Recognition Test, PST Picture Sequencing Task, TASIT The Awareness of Social Inference Test, ToM theory of mind, WM working memory, 0 no significant association $(p>0.05)$ 
emotion processing (social-perceptual part), an exception involves a paper which investigated emotion processing using the paralanguage subtest (by the tone of voice) and found no significant difference to the control group [53]. This could imply that auditory emotion processing is intact in persons with 22q11DS. However, given that this was the only study that used auditory stimuli to assess this aspect of social cognition and reported that the sample size $(n=66)$ might not be large enough to detect significant group differences, this finding should be interpreted with caution and warrants further examination. In the domain of ToM (socialcognitive part), three studies reported no significant differences between individuals with 22q11DS and the control group [50,54,55] that were interpreted mainly in relation to the age of the sample, as it will be further discussed.

Regarding the assessments of social cognitive domains, two elements are notable. First, one paper compared 22q11DS individuals with/without autism spectrum disorder (ASD) to a control group using abstract, ambiguous visual stimuli to assess ToM abilities [52]. The finding confirms that individuals with 22q11DS, regardless of ASD, have significant ToM impairments in both the ability to explain purposeful behavior (Intentionality) and to accurately describe the events going on in the scene (Appropriateness). This was the only study that did not rely on verbal comprehension to assess ToM making it more optimal for children with the syndrome. Nevertheless, implicit mentalizing was also impaired in individuals with 22q11DS [52]. Second, social perception and attributional bias have been merely researched in individuals with 22q11DS: only one study assessed social perception [57] and no research examined attributional bias. Additionally, a paper that assessed social perception did not investigate the relation of this aspect of social cognition to psychopathology or social outcomes [57].

\section{Links between social cognitive domains and psychopathology}

One of the main goals of our study was to review the association between social cognition and psychopathology, and three studies confirmed medium effect size associations between emotion processing and negative symptoms of psychosis $[49,56,58]$. This finding is also supported by the research of Jalbrzikowski et al. in which emotion processing was found to be specifically associated with negative symptoms [21]. A paper that did not observe a significant association between emotion processing and negative symptoms involved a total score for social cognition (including emotion identification, differentiation, and age differentiation) [59]. However, a significant association was observed between a global neurocognitive performance (GNP) score from the Penn Computerized Neurocognitive Battery (CNB) (including executive function, episodic memory, complex cognition, social cognition, and praxis speed) and negative symptoms. Specifically, GNP at baseline significantly predicted the emergence and persistence of negative symptoms at a fifteen-month follow-up [59]. Even if neurocognition and social cognition are conceptualized as distinct constructs, there is a significant overlap between them [19]. Altogether, these findings might imply that aspects of social cognition, specifically emotion processing, does play a role in the emergence of negative symptoms, however, in a manner that also involves other neurocognitive domains. Theory of mind was also found to be associated with negative symptoms $[49,55]$, which is in line with the reports from Frascarelli et al. [60] and the research on persons with schizophrenia [18]. Findings on risk and outcome in psychosis have already indicated that social cognitive domains might share the same etiological origin with negative symptoms [61], which seems to be in line with the current state of research on individuals with 22q11DS. Given that the severity of negative symptoms is a clinical characteristic of 22q11DS [62, 63], these findings highlight both aspects of social cognition (emotion processing and ToM) as possible targets for intervention strategies aimed at reducing the severity of negative symptoms in this population.

Two elements regarding the associations between social cognitive domains and positive or emotional symptoms should be noted. First, only one of the included studies reported a significant association between emotion processing and positive (paranoid) symptoms [56] and one reported a significant association only after removing participants who were on antipsychotic medication [55]. In contrast, two papers reported no significant association between either aspect of social cognition and positive symptoms [49, 52]. However, two studies that were not eligible for the present review (as they have not assessed social outcomes) reported links between emotion processing [64] and ToM [21] and positive symptoms in persons with 22q11DS. Research on schizophrenia grossly confirmed associations between social cognitive domains and positive symptoms, but these reported associations were also interpreted with caution warranting additional considerations $[61,65,66]$. By way of example, one study reported that high levels of positive symptoms were associated with the deficits in social cognition only in the presence of high levels of negative symptoms [67]. Second, only one included study investigated links between emotion processing and internalizing (anxiety/ depression) symptoms in individuals with 22q11DS [58]. This paper reported no significant association among two domains, possibly due to the use of less 
thorough anxiety assessment [58]. Conversely, findings outside the scope of the present search reported links between unusual face processing (specifically, less time spent on eyes) and (self-reported) anxiety as well as (parent-reported) internalizing behavior [26, 27]. Additionally, the importance of emotional processes on the clinical expression of positive symptoms has been recognized for persons with 22q11DS [56] and in research on schizophrenia [68]. This implies that the relationship between social cognitive domains and positive symptoms is more complex and possibly requires consideration of other symptomatology. Given that the current state of research regarding the 22q11DS population is limited and given the predominant focus on positive and negative symptoms, future studies should consider focusing on an early tracking of emotional symptoms (e.g., anxiety/depression). For instance, a longitudinal design could elucidate the role of specific social cognitive deficits in relation to emotional symptoms at different time points and the possible path of progression to positive symptoms.

\section{Links between social cognitive domains and social outcomes}

Our review highlights that the associations between social cognitive domains and social outcomes are inconsistent. Four studies found no significant association between emotion processing and social outcomes. In contrast, four papers confirmed the association [50, 54, $55,58]$, but one article used the PANSS negative symptoms scores as a measure of social abilities [58], a tool initially designed to assess positive and negative symptoms of psychosis. A similar result was also found regarding the associations between ToM and social outcomes: three studies reported no significant association $[49,54,55]$ to social outcomes and two papers observed significant links [50, 52]. This finding is not surprising considering the current state of research on schizophrenia in this respect. Although the prominent view is that social cognition has a mediating role between neurocognition and social functioning [32, 69, 70], several studies found no associations between these two domains [43, 47, 48]. Both findings invite for a closer understanding of the reported results. For example, social cognition (social perception) was specifically predictive of work, but not of social functioning in persons with psychosis [43]. Furthermore, the severity of symptoms reduced the strength of the association between social cognition and social outcomes [48]. Results of the present review are divided for any conclusive interpretation in this respect. However, the studies that did observe significant association between both parts of social cognition and social outcomes involved larger samples, and could therefore be accounted as more representative. It can be that the association between two respective domains changes at different time points and is influenced by the severity of symptoms, which warrants further investigation in population with 22q11DS..

It should be noted that given the highly complex nature of social outcomes (skills, competence, functioning), the operationalization of both constructs in an ecologically valid manner that can be compared across studies remains challenging [47]. In the present review, the social outcomes of individuals with 22q11DS were assessed by parent ratings in almost all included studies. At the same time, discrepancies regarding social outcomes in parent vs. teacher [71], or parent vs. child and sibling were observed in the group of participants with 22q11DS [72]. Therefore, it is questionable whether the parent-ratings of social outcomes are sensitive enough to observe a specific association with social cognition in individuals with 22q11DS. In this respect, suggestions regarding the need for multi-rater assessments, using multiple instruments for social-behavioral functioning have already been made [61] and should be considered in future studies.

\section{Links between social cognitive domains and other variables}

In the terms of relationship to other tested variables (age, IQ, WM, EF), age emerged to be significantly associated with social cognition in most included studies. Older participants were found to perform better in emotion processing tasks $[49,50]$. Additionally, a longitudinal analysis pointed that individuals with 22q11DS from the age of 6 years old improved to a lesser extent than typically developing controls in emotion (configural) processing (comparing original face photo of a woman to the versions of photos of the same woman, but with eyes/mouth being moved up, down, further or closer) [58]. With respect to ToM, several studies reported no significant group differences that was interpreted in relation to age. Specifically, Badoud et al. reported that both groups performed low on a perspective taking task [55] and Campbell et al. observed that both children with 22q11DS and controls passed simpler (first-order) false-belief tasks [50]. All the children who failed ToM tasks were in the age group between 6 and 9 years old. There is a need for additional longitudinal studies to better understand the developmental trajectories of social cognitive domains in persons with 22q11DS (but see [33]). Even though the current state of research is still modest for conclusions in this respect, reported findings point to social cognitive developmental deficits or delays that seem to manifest significant differences to typical development before 
the age of 6 years old in children with the syndrome. This implies that preventive strategies are to be considered very early and prior to the specified age.

Interestingly, only two included studies reported associations between emotion processing [49] and ToM [52] and IQ, and five papers found no association between these domains $[49,52,53,55,58]$. The article which observed a significant association between ToM and IQ reported different results at two sites depending on the format of the instruction provided to the individuals with 22q11DS [52]. Given that individuals with 22q11DS are in most cases characterized by borderline intellectual functioning and mild intellectual disability, this finding highlights that special consideration should be taken regarding the way in which ToM is assessed and the choice of instrument for this specific population. Concerning the association between neurocognition and social cognition, findings are limited as only three included papers investigated this association [50, 53, 54]. Links were reported between emotion processing and WM [50] and between ToM and EF [54]. It would be useful to further understand the influence of neurocognition on social cognitive domains using longitudinal designs.

\section{Clinical implications and treatment suggestions}

The current state of research on interventions for persons who are at the risk for schizophrenia/psychosis recommends approaches that can be applied early in life in order to improve concrete aspects of the atypical developmental trajectory, and prior to the appearance of severe psychopathology, functional impairment, or diagnosable disorder [73]. Given that individuals with 22q11DS are at increased risk for the development of psychosis, early detection of vulnerable domains, such as social cognition, and the impact of other variables during the course of development would possibly lead to the timely implementation of strategies that would improve concrete aspects of development. Additionally, it has been reported that parents of children with 22q11DS can be at increased risk for burnout [74]. Considering the role of caregivers in the development of the mentalizing capacity of children [75], which might be compromised in the case of overwork or burnout, intervention strategies may consider involving the affected children and their parents.

Although associations among studied domains in a population with 22q11DS are complex and sometimes inconsistent, they can be informative of possible preventive strategies. Concerning social cognition specifically, a proposition has already been made for the inclusion of the assessment of this domain as a potential biomarker and a screening tool for various clinical conditions in the general population [23]. In the context of individuals with 22q11DS, a longitudinal monitoring of this domain in affected children could be used to broaden our understanding of clinical and social outcomes.

With respect to the concrete preventive strategies, research on the effectiveness of specific interventions in this specific population is still modest. Therefore, possible strategies can currently be made mainly in the form of psychoeducational recommendations. For example, studies in the present review confirm associations between both social cognitive domains and predominantly negative symptoms of psychosis [49, 55, 56, 58]. Even if additional (especially longitudinal) research is required, the current body of evidence suggests that early intervention focusing on emotion perception and ToM could possibly lead to the prevention of negative symptoms, which in turn may impact better functional outcomes. Interventions targeting emotion processing designed specifically for children with 22q11DS, such as vis-à-vis program [76] have already been proposed. Additionally, social cognitive remediation appropriated for children has also been suggested [77]. In the field of schizophrenia, a combined intervention for neurocognition and social cognition has been proposed [78, 79], notably including computer-aided sessions or individual/group settings involving discussions on social scenes, interactions, or role-playing.

At the same time, worthy of note is that early deficits related to social cognitive domains are often coupled with the challenges of various physical conditions that are characteristic of the syndrome and that affect both children and their parents. For this reason, a possible strategy could consider engaging immediate surrounding in a manner that would create (an early) preventive environment. With respect to the domains of social cognition specifically, parental embodied mentalizing (PEM) [80] and mentalization based treatment (MBT) [75] can be of relevance. Both approaches emphasize the interpersonal environment for emotion regulation and the development of mentalizing capacity. Additionally, MBT has been proven to be effective for individuals with psychosis especially during the early phase of illness [81]. However, heterogeneity of the 22q11DS population and impaired cognitive capacities of some individuals should be underlined and would require further investigation in terms of preventive strategies. Equally, given that aspects of social cognition (e.g., ToM) continue to improve during adolescence and early adulthood [31], but at the same time may manifest developmental delays already in childhood in the 22q11DS population, age is an additional factor to be considered. This may also mean that interventions, entailing specific (neurocognitive and social cognitive) domains for the specific age, could be personalized for each child (family) affected with the syndrome. The importance of including the environment (parents and other clinicians) is not only 
essential for the necessary improvements of early social cognitive deficits, but also for the timely detection of changes in the behavior that might lead to symptoms. Rather than focusing primarily on the psychiatric profiles and diagnosis, early uncovering and understanding of such behaviors is important for implementing preventive and intervention strategies, as it has already been recognized in the 22q11DS population [7].

\section{Strengths, limitations, future orientation}

The present review points to several strengths and limitations regarding the current state of research on social cognitive domains in individuals with 22q11DS and its links with psychopathology and social outcomes. With respect to participants, affected groups were recruited mainly from parent associations (not mental-health related) and control groups from the local community using the appropriate selection strategy, therefore minimizing the risk of selection bias. All included studies involved individuals with confirmed 22q11DS, including age- and gender-matched controls, which eliminated confounding in this respect. Most studies did not match the groups on IQ and did not control for this variable in group comparisons. Given that difference in IQ is an inherent property of the grouping, it would be statistically improper to control for differences in this aspect in the comparisons [82]. Studies in the review focused on two aspects of social cognition - emotion processing and theory of mind - using tasks similar to those used in schizophrenia research. This makes it relatively easy to contrast the obtained findings with those acquired on individuals with schizophrenia/psychosis.

At the same time, investigation of the links between chosen domains is complex and several points need to be highlighted. First, except for two studies that employed longitudinal designs [58, 59], all included papers used a cross-sectional design that intrinsically provides limited quality of evidence. Due to the heterogeneity of included studies and reported data, it was not possible to conduct a meta-analysis, thus the review is a narrative synthesis of provided evidence. Clinical diversity of the studied population is a major issue that has likely contributed to the inconsistency of the reported results. Factors such as psychiatric comorbidities, the severity of symptoms, use of medication could be considered as potential confounders. For example, studies varied on the inclusion of participants with a psychotic disorder or whether they reported other psychiatric comorbidities and use of medication. Additionally, none of the mentioned factors could be suggested as a potential moderator due to underreporting and the lack of precisely conducted moderator analysis. In order to avoid these limitations, future research could consider classifying subgroups of affected individuals based on their clinical features and/or social outcomes. This would possibly clarify the nature of the reported associations across groups of affected individuals, particularly in the context of formerly suggested longitudinal designs.

Second, overlapping and distinct aspects of the concepts behind chosen domains including diverse sensitivity and precision of the instruments used for evaluation is a recurrent theme in the field. This invites special consideration that is beyond the focus of the present study and requires separate research. In most included studies, domains of interest were assessed by validated instruments specifically designed for the assessment of each respective domain. The exception involves a study that used the PANSS negative symptoms scale [12], which is designed for the assessment of negative symptoms of psychosis as the measurement of social outcomes [58]. Another paper focusing on dysfunctional beliefs was included and categorized under the social outcomes measurement [56]. However, included studies varied in the precision of the instruments that were used. Given the wide range and complexity of the chosen constructs, future studies should employ strategies that minimize the overlapping aspects of these domains and try to focus the investigation on the facets that exclusively stand for each construct. By way of example, excluding decreased experience of emotions and social withdrawal subscales from the measurements of psychopathology, as these may rather reflect social cognition and social outcomes respectively. Similarly, in instruments that are used for the assessments of both psychopathology and social outcomes (e.g., SDQ), it should be useful to divide analysis for each subscales and items that uniquely stand for each domain.

Third, there is a clear gap in knowledge on social perception and attributional bias for this specific population, which should be addressed in future research. Concerning the specific tools for the assessment of social cognition, only two studies reported using instruments specifically designed for research with children with developmental disorders $[50,54]$. Limitation regarding the choice of stimuli, tools, and tasks that are used for social cognitive domains has already been acknowledged in the field. Regarding emotion processing, one of the concerns is that static portraits of face photos do not match the complexity of variations in facial expressions in daily life or social interactions. Regarding the assessment of ToM, a major criticism is that participants have an observer role and are required to infer the mental states of individuals with whom they are not interacting. Additionally, certain tasks used for ToM rely on the verbal understanding, other neurocognitive measures (e.g., WM), or are influenced by the format of directions provided to the participants (due to their IQ range), which should be considered in the research for this specific population. The use of dynamic stimuli and more 
naturalistic assessments (e.g., clinical interviews to evaluate mentalization) could be an option to minimize these limitations. The proposition of the SCOPE study [24] for measures with the strongest psychometric properties $[66,83,84]$ could also be of relevance. At the same time, recommendation for the most appropriate instruments for social cognitive domains specifically for the 22q11DS population would be useful in order to overcome these limitations.

Fourth, concerning the investigated links in the present study, six included papers reported on the links between social cognitive domains and psychopathology $[49,52,55,56,58,59]$ and all but one paper [59] reported associations with social outcomes. The inclusion criteria of the present review required studies to involve assessments of all domains of interest and to report the links between social cognitive domains and psychopathology and/or social outcomes. In the selection process, 12 studies were excluded as they have not investigated nor reported the associations of interest (inclusion criterion number four), even though they had assessed all domains of interest. In contrast, several studies that were excluded due to the lack of the assessments of either psychopathology or social outcomes, sometimes did report associations we were interested in. This was mainly regarding the links between social cognition and psychopathology. The inclusion of such papers would have broadened the scope of the review in a manner that warrants a new study. We tried to overcome this limitation by complementing discussion with the very findings from the excluded papers and are confident that no data we were interested in was lost due to this limitation.

Finally, the cross-sectional design used by most included studies does not allow a possibility for causal interpretations. Future longitudinal research should be conducted in order to have the possibility to investigate the directionality of the observed findings. This will provide a better understanding of the nature behind reported links and will secure timely preventive strategies for this population. Specifically, the acquired knowledge will inform on the necessity of the concrete prevention strategy targeting a specific domain for the specific age and will warrant the evolution of preventive strategies for individuals with 22q11DS.

\section{Conclusion}

Research on the links between social cognitive domains and psychopathology as well as social outcomes in persons with 22q11DS is in its developing stage since only ten studies fitted the eligibility criteria for the present review. Interestingly, even when studies involved domains of interest, many did not investigate the associations to social cognition specifically, but focused on the associations between other aspects (i.e., psychopathology and social outcomes, neurocognitive variables and social outcomes). Along with the current state of research on schizophrenia, results of the present review provide sufficient evidence that social cognition is domain of interest to broaden our understanding of clinical outcomes and social difficulties in persons with 22q11DS. Indeed, significant associations between both social cognitive domains (emotion processing and ToM) and negative symptoms have been reported by several studies [21, 49, $55,56,58,60]$. Concerning positive symptoms, the association seems to be more complex in that it possibly involves the impact of other aspects (e.g., neurocognition, emotional symptoms) and requires further research. Even though most studies focused primarily on investigating the associations between social cognitive domains and positive and negative symptoms of psychosis, the role of other symptoms and variables should not be underestimated. At the same time, due to the wide range and complexity of these respective domains, assessment strategies should aim to investigate the facets that uniquely represent each construct and minimize the potential overlap between them. Given that the affected persons are at risk for psychopathological manifestations and social difficulties, longitudinal studies that can monitor the development of social cognitive domains, the impact of neurocognition and emotional symptoms at different time points would provide a better understanding of affected persons and the progression to various clinical outcomes. Accumulated knowledge would provide informed decisions about timely preventive strategies that can be applied for individuals with 22q11DS and their environment.

\section{Supplementary Information}

The online version contains supplementary material available at https://doi. org/10.1186/s12888-020-02975-5.

Additional file 1. Assessments of social cognitive domains,

psyschopathology, social outcomes, and neurocognition [12, 13, 24, 30 , 31, 66, 83-121].

\footnotetext{
Abbreviations

22q11DS: 22q11 deletion syndrome; ABAS-II: The Adaptive Behavior Assessment System—Sec. Ed.; ABCL: Adult behavior checklist ; ADHD: Attention deficit hyperactivity disorder; ADI-R: Autism Diagnostic Interview-Revised; ADOS: Autism Diagnostic Observation Schedule; ASD: Autism spectrum disorders; ASR: Adult self-report; BFRT: Benton Facial Recognition Test; BLERT: Bell Lysaker Emotion Recognition Task; CBCL: Child behavioral checklist; CD trial: Configural different trial; C-DISC: Diagnostic Interview Schedule for Children; DANVA: Diagnostic Analysis of Non-Verbal Accuracy; DAS: Dysfunctional Attitude Scale-Form A; DICA: Diagnostic Interview for Children and Adolescents; EAT: Emotion Attribution Task; EF: Executive function; EP: Emotion processing; ERT: Emotion Recognition Task; FD trial: Featural different trial; FISH: Fluorescence in Situ Hybridization; GAF: Global Assessment of Function; IAPS: International Affective Picture System; IQ: Intelligence quotient; K-SADS-PL: Schedule for Affective Disorders and Schizophrenia for School-Age Children - Present and Lifetime; PANS S: Positive and Negative Syndrome Scale; PRISMA: Preferred Reporting Items for Systematic Reviews and Metanalysis; PST: Picture Sequencing Task; QF-
} 
PCR: Quantitative Fluorescence Polymerase Chain Reaction; RT: Response time; SADS: Schedule for Affective Disorders and Schizophrenia for SchoolAge Children; SCID: Structured Clinical Interview for DSM IV, Axis I Disorders; SCOPE: Social Cognition Psychometric Evaluation; SDQ: Strengths and Difficulties, Questionnaire; SIPS: Structured Interview for Prodromal Syndromes; SOPS: Scale of Prodromal Symptoms; SPQ: Schizotypal Personality Questionnaire; SRS: Social Responsiveness Scale; SSRS: Social Skills Rating System; TASIT: The Awareness of Social Inference Test; ToM: Theory of Mind; VABS: Vineland Adaptive Behavior Scales; WM: Working memory; YSR: Youth self-report

\section{Acknowledgements}

Not applicable.

\section{Authors' contributions}

BM Conduct of the search in databases (PubMed and PsycINFO). Systematic review including study selection, data extraction, and quality assessment in collaboration with CF. Identification of key findings and manuscript structure. Major contributor in drafting of the initial and final version of the manuscript. CF Active involvement in study selection, data extraction, and quality assessment. Content expertise and review of the draft versions of the manuscript. MS Active involvement in the design, structure, and scope of the study. Content expertise on social cognition and 22q11DS. Review of the draft versions of the manuscript. MD Advisory support to BM regarding the initial idea, scope and design of the study. Active involvement in study selection and collaborative drafting of the manuscript structure. Content expertise on social cognition and 22q11DS. Review of the draft versions of the manuscript. HLS Advisory support to BM regarding the study design, review, and quality assessment. Content expertise and review of the draft versions of the manuscript. All authors read, contributed to and approved the final manuscript.

\section{Funding}

The present research is supported by the European Cooperation in Science and Technology (COST), action TREATme (STSM) and the American Psychoanalytic Association (APsaA). Maude Schneider is supported by an Ambizione Grant from the Swiss National Science Foundation (PZOOP1_174206). The funding bodies had no role in the design of the study and collection, analysis and interpretation of data and in writing the manuscript.

\section{Availability of data and materials}

The datasets used and/or analyzed during the current study are available from the corresponding author on reasonable request.

\section{Ethics approval and consent to participate}

Not applicable.

\section{Consent for publication}

Not applicable.

\section{Competing interests}

The authors declare that they have no competing interests.

\section{Author details}

Clinic for Psychoanalysis and Psychotherapy, Medical University of Vienna, Vienna, Austria. ${ }^{2}$ Clinical Psychology Unit for Intellectual and Developmental Disabilities, Faculty of Psychology and Educational Sciences, University of Geneva, Geneva, Switzerland. ${ }^{3}$ Developmental Clinical Psychology Unit, Faculty of Psychology and Educational Sciences, University of Geneva, Geneva, Switzerland. ${ }^{4}$ Research Department of Clinical, Educational and Health Psychology, University College London, London, UK.

Received: 21 July 2019 Accepted: 18 November 2020 Published online: 06 March 2021

\section{References}

1. Ardinger $\mathrm{HH}$, Ardinger $\mathrm{RH}$. Clinical presentation of velo-cardio-facial syndrome. Prog Pediatr Cardiol. 2002;15:93-7.

2. Olsen L, Sparso T, Weinsheimer SM, Bertalan Quintanilha Dos Santos M, Mazin W, Rosengren A, Sanchez XC, Hoeffding LK, Schmock H, BaekvadHansen M, Bybjerg-Grauholm J, Daly MJ, Neale BN, Pedersen MG, Agerbo E,
Mors O, Borglum A, Nordentoft M, Hougaard DM, Mortensen PB, Geschwind DH, Pedersen C, Thompson WK, Werge T. Prevalence of rearrangements in the $22 q 11.2$ region and population-based risk of neuropsychiatric and developmental disorders in a Danish population: a case-cohort study. Lancet Psychiatry. 2018;7(5):573-80.

3. Oskrsdottir S, Vujic M, Fasth A. Incidence and prevalence of the 22q11 deletion syndrome: a population-based study in Western-Sweden. Arch Dis Child. 2004;89(2):148-51.

4. Botto LD, May K, Fernhoff PM, Correa A, Coleman K, Rasmussen SA, Mahle WT. A population-based study of the 22q11.2 deletion: phenotype, incidence and contribution to major birth defects in the population. Pediatrics. 2003;112(1):101-7.

5. Scambler PJ. The 22q11 deletion syndromes. Hum Mol Genet. 2000;9(16):2421-6.

6. Insel TR. Rethinking schizophrenia. Nature. 2010;468(7321):187-93.

7. Fiksinski AM, Schneider M, Murphy CM, Armando M, Vicari S, Canyelles JM, Gothelf D, Eliez S, Breetvelt EJ, Arango C, Vorstman JAS. Understanding the pediatric psychiatric phenotype of 22q11.2 deletion syndrome. Am J Med Genet A. 2018;176(10):2182-91.

8. Schneider M, Debbané $M$, Bassett AS, Chow EW, Fung WL, van den Bree $M$, Owen M, Murphy KC, Niarchou M, Kates WR, Antshel KM, Fremont W, DM MD-MG, Gur RE, Zackai EH, Vorstman J, Duijff SN, Klaassen PW, Swillen A, Gothelf D, Green T, Weizman A, Van Amelsvoort T, Evers L, Boot E, Shashi V, Hooper SR, Bearden CE, Jalbrzikowski M, Armando M, Vicari S, Murphy DG, Ousley O, Campbell LE, Simon TJ, Eliez S. International Consortium on Brain and Behavior in 22q11.2 Deletion Syndrome. Psychiatric disorders from childhood to adulthood in 22q11.2 deletion syndrome: results from the International Consortium on Brain and Behavior in 22q11.2 Deletion Syndrome. Am J Psychiatry. 2014;171(6):627-39.

9. Green T, Gothelf D, Glaser B, et al. Psychiatric disorders and intellectual functioning throughout development in velocardiofacial (22q11.2 deletion) syndrome. J Am Acad Child Adolesc Psychiatry. 2009;48(11):1060-8.

10. Duijff SN, Klaassen PW, de Veye HF, Beemer FA, Sinnema G, Vorstman JA. Cognitive development in children with 22q11.2 deletion syndrome. $\mathrm{Br}$ J Psychiatry. 2012;200(6):462-8.

11. Kates WR, Tang KL, Ansthel KM, Fremont WP. Behavioral and psychiatric phenotypes in 22q11.2 deletion syndrome. J Dev Behav Pediatr. 2015;36(8): 639-50.

12. Kay SR, Fiszbein A, Opler LA. The positive and negative syndrome scale (PANSS) for schizophrenia. Schizophr Bull. 1987;13(2):261-76.

13. Raine A. The SPQ: a scale for the assessment of schizotypal personality based on DSM-III-R criteria. Schizophr Bull. 1991;17:555-64.

14. Swillen A, Devriendt K, Legius E, Eyskens B, Dumoulin M, Gewillig M, et al. Intelligence and psychosocial adjustment in velocardiofacial syndrome: a study of 37 children and adolescents with VCFS. J Med Genet. 1997;34:453-8.

15. Shprintzen R. Velo-cardio-facial-syndrome: a distinctive behavioural phenotype. Ment Retard Dev Disabil Res Rev. 2000;6(2):142-7.

16. Feinstein C, Eliez S, Blasey C, Reiss AL. Psychiatric disorders and behavioral problems in children with velocardiofacial syndrome: usefulness as phenotypic indicators of schizophrenia risk. Biol Psychiatry. 2002;51:312-8.

17. Roizen NJ, Antshel KM, Fremont W, AbdulSabur N, Higgins AM, Shprintzen RJ. 22q11.2DS deletion syndrome: developmental milestones in infants and toddlers. J Dev Behav Pediatr. 2007;28:119-24.

18. Penn DL, Sanna LJ, Roberts DL. Social cognition in schizophrenia: an overview. Schizophr Bull. 2008;34(3):408-11.

19. Green MF, Bearden CE, Cannon TD, Fiske AP, Hellemann GS, Horan WP, Kee K, Kern RS, Lee J, Sergi MJ, Subotnik KL, Sugar CA, Ventura J, Yee CM, Nuechterlein $\mathrm{KH}$. Social cognition in schizophrenia, part 1: performance across phase of illness. Schizophr Bull. 2012;38(4):854-64.

20. Chow EWC, Watson M, Young DA, Bassett AS. Neurocognitive profile in 22q11 deletion syndrome and schizophrenia. Schizophr Res. 2006;87(1-3):270-8.

21. Jalbrzikowski M, Carter C, Senturk D, Chow C, Hopkins JM, Green MF, Galván A, Cannon TD, Bearden CE. Social cognition in 22q11.2 microdeletion syndrome: relevance to psychosis? Schizophr Res. 2012;142(1-3):99-107.

22. Adolphs R. The social brain: neural basis of social knowledge. Annu Rev Psychol. 2009;60:693-716.

23. Cotter J, Granger K, Backx R, Hobbs M, Looi CY. Social cognitive dysfunction as a clinical marker: a systematic review of meta-analyses across 30 clinical conditions. Neurosci Biobehav Rev. 2018;84:92-9.

24. Pinkham AE, Penn DL, Green MF, Buck B, Healey K, Harvey PD. The social cognition psychometric evaluation study: results of the expert survey and RAND panel. Schizophr Bull. 2014;40(4):813-23. 
25. Lajiness-O'Neill RR, Beulieu I, Titus JB, Asamoah A, Bigler ED, Bawle EV. Memory and learning in children with 22q1.2 deletion syndrome: evidence for ventral and dorsal stream distruption? Child Neuropsychology. 2005;11:55-71.

26. Glaser $B$, Debbané $M$, Ottet MC, Vuilleumier $P$, Zesiger $P$, Antonarakis SE, Eliez $S$. Eye gaze during face processing in children and adolescents with 22q11.2 deletion syndrome. J Am Acad Child Adolesc Psychiatry. 2010;49(7): 665-74.

27. Campbell L, McCabe K, Leadbeater K, Schall U, Loughland C, Rich D. Visual scanning of faces in 22q11.2 deletion syndrome: attention to the mouth or the eyes? Psychiatry Res. 2010;177:211-5.

28. Gur RE, Yi JJ, McDonald-McGinn DM, Tang SX, Calkins ME, Whinna D, Souders MC, Savitt A, Zackai EH, Moberg PJ, et al. Neurocognitive development in 22q11.2 deletion syndrome: comparison with youth having developmental delay and medical comorbidities. Mol Psychiatry. 2014; 19(11):1205-11.

29. Yi JJ, Weinberger R, Moore TM, Calkins ME, Guri Y, McDonald-McGinn DM, Zackai EH, Emanuel BS, Gur RE, Gothelf D, Gur RC. Performance on a computerized neurocognitive battery in 22q11.2 deletion syndrome: a comparison between US and Israeli cohorts. Brain Cogn. 2016;106:33-41.

30. Castelli F, Frith C, Happe F, Frith U. Autism, Asperger syndrome and brain mechanisms for the attribution of mental states to animated shapes. Brain. 2002;125:1839-49.

31. Dumontheil I, Apperly IA, Blakemore S-J. Online usage of theory of mind continues to develop in late adolescence. Dev Sci. 2010;13:331-8.

32. Green MF, Horan WP, Lee J. Nonsocial and social cognition in schizophrenia: current evidence and future directions. World Psychiatry. 2019;18:146-61.

33. Norkett EM, Lincoln SH, Gonzales-Heydrich J, D'Angelo EJ. Social cognitive impairment in 22q11 deletion syndrome: a review. Psychiatry Res. 2017;253: 99-106.

34. Chakrabarti B, Baron-Cohen S. Empathizing: neurocognitive developmental mechanisms and individual differences. In: Anders S, Ende G, Junghofer M, Kissler J, Wildgruber D, editors. Understanding emotions. Amsterdam: Elsevier; 2006. p. 403-18.

35. Green MF. What are the functional consequences of neurocognitive deficits in schizophrenia? Am J Psychiatry. 1996;153:321-30.

36. Smith T, Bellack A, Liberman R. Social skills training for schizophrenia: review and future directions. Clin Psychol Rev. 1996;16:599-617.

37. Kohler CG, Bilker W, Hagendoorn M, Gur RE, Gur RC. Emotion recognition deficit in schizophrenia: association with symptomatology and cognition. Biol Psychiatry. 2000:48(2):127-36.

38. Inoue $Y$, Yamada K, Hirano M, Shinohara M, Tamaoki T, Iguchi H, Tonooka Y, Kanba S. Impairment of theory of mind in patients in remission following first episode of schizophrenia. Eur Arch Psychiatry Clin Neurosci. 2006;256(5): 326-8.

39. Yi JJ, Calkins M, Tang SX, Kohler C, McDonald-McGinn DM, Zackai EH, Savitt AP, Bilker WB, Whinna DA, Souders MC, Emanuel BS. Impact of psychiatric comorbidity and cognitive deficit on function in 22q11.2 deletion syndrome. J Clin Psychiatry. 2015;76(10):e1262-70.

40. Tang SX, Moore TM, Calkins ME, Yi JJ, Savitt A, Kohler CG, Souders MC, Zackai EH, McDonald-McGinn DM, Emanuel BS, Gur RC, Gur RE. The psychosis spectrum in 22q11.2 deletion syndrome is comparable to that of non-deleted youths. Biol Psychiatry. 2017;82(1):17-25.

41. Fett $A K$, Viechtbauer $W$, Dominguez MD, et al. The relationship between neurocognition and social cognition with functional outcomes in schizophrenia: a meta-analysis. Neurosci Biobehav Rev. 2011;35:573-88.

42. McCleery A, Lee J, Fiske AP, et al. Longitudinal stability of social cognition in schizophrenia: a 5-year follow-up of social perception and emotion processing. Schizophr Res. 2016;176:467-72.

43. Horan WP, Green MF, DeGroot M, et al. Social cognition in schizophrenia, part 2: 12-month stability and prediction of functional outcome in firstepisode patients. Schizophr Bull. 2012:38:865-72

44. Couture SM, Penn DL, Roberts DL. The functional significance of social cognition in schizophrenia: a review. Schizophr Bull. 2006;32(Suppl. 1):44-63

45. Kee KS, Green MF, Mintz J, Brekke JS. Is emotion processing a predictor of functional outcome in schizophrenia? Schizophr Bull. 2003;29:487-97.

46. Brüne M, Schaub D, Juckel G, Langdon R. Social skills and behavioral problems in schizophrenia: the role of mental state attribution, neurocognition and clinical symptomatology. Psychiatry Res. 2011;190:9-17.

47. Simons CJ, Bartels-Velthuis AA, Pijnenborg GH. Cognitive performance and long-term social functioning in psychotic disorder: a three-year follow-up study. PLoS One. 2016;2016. https://doi.org/10.1371/journal.pone.0151299.
48. Schneider M, Myin E, Myin-Germeys I. Is theory of mind a prerequisite for social interactions? A study in psychotic disorder. Psychol Med. 2019;50(5): 754-60

49. Vangkilde A, Jepsen JR, Schmock H, Olesen C, Arnarsdóttir S, Baaré WF, Plessen KJ, Didriksen M, Siebner HR, Werge T, Olsen L. Associations between social cognition, skills, and function and subclinical negative and positive symptoms in 22q11.2 deletion syndrome. J Neurodev Disord. 2016:8:42

50. Campbell LE, Stevens AF, McCabe K, Cruickshank L, Morris RG, Declan GM, Murphy DGM, Kieran C, Murphy KC. Is theory of mind related to social dysfunction and emotional problems in 22q11.2 deletion syndrome (velocardio-facial syndrome)? J Neurodev Disord. 2011;3(2):152-61.

51. Moher D, Liberati A, Tetzlaff J, Altman DG. Preferred reporting items for systematic reviews and meta-analyses: the PRISMA statement. Ann Intern Med. 2009:151:264-9.

52 Ho JS, Radoeva PD, Jalbrzikowski M, Chow C, Hopkins J, Tran WC, Mehta A, Enrique N, Gilbert C, Antshel KM, Fremont W, Kates WR, Bearden CE. Deficits in mental state attributions in individuals with 22q11.2 deletion syndrome (velo-cardio-facial syndrome). Autism Res. 2012;5(6):407-18.

53. Shashi V, Veerapandiyan A, Schoch K, Kwapil T, Keshavan M, Ip E, Hooper S. Social skills and associated psychopathology in children with chromosome 22q11.2 deletion syndrome: implications for interventions. J Intellect Disabil Res. 2012:56(9):865-78

54. Campbell LE, McCabe KL, Melville JL, Strutt PA. Schall U. social cognition dysfunction in adolescents with 22q11.2 deletion syndrome (velo-cardiofacial syndrome): relationship with executive functioning and social competence/functioning. J Intellect Disabil Res. 2015;59(9):845-59.

55. Badoud D, Schneider M, Menghetti S, Glaser B, Debbané M, Eliez S. Understanding others: a pilot investigation of cognitive and affective facets of social cognition in patients with 22q11.2 deletion syndrome (22q11DS). J Neurodev Disord. 2017;9:35.

56. Schneider M, Van der Linden M, Menghetti S, Debbané M, Eliez S. Negative and paranoid symptoms are associated with negative performance beliefs and social cognition in 22q11.2 deletion syndrome. Early Interv Psychiatry. 2017;11(2):156-64

57. Dubourg L, Vrticka P, Debbané M, Chambaz L, Eliez S, Schneider M. Neural correlates of socio-emotional perception in 22q11.2 deletion syndrome. J Neurodev Disord. 2018;10(1):13.

58. Zaharia A, Schneider M, Glaser B, Franchini M, Menghetti S, Schaer M, Debbané M, Eliez S. Face processing in 22q11.2 deletion syndrome: atypical development and visual scanning alterations. J Neurodev Disord. 2018;10(1):26.

59. Weinberger R, Weiseman O, Guri Y, Harel T, Weizman A, Gothelf D. The interaction between neurocognitive functioning, subthreshold psychotic symptoms and pharmacotherapy in 22q11.2 deletion syndrome: a longitudinal study. Eur Psychiatry. 2018;48:20-6.

60. Frascarelli M, Padovani G, Buzzanca A, Accinni T, Carlone L, Ghezzi F, Lattanz GM, Fanella M, Putotto C, Di Bonaventura C, Girardi N, Pasquini M, Biondi M, Di F. Social cognition deficit and genetic vulnerability to schizophrenia in 22q11 deletion syndrome. Ann Ist Super Sanita. 2020;56(1):107-13.

61. Fett AKJ, Maat A, GROUP Investigators. Social cognitive impairments and psychotic symptoms: what is the nature of their association? Schizophr Bull. 2013;39(1):77-85.

62. Armando $M$, Girardi $P$, Vicari $S$, et al. Adolescents at ultrahigh risk for psychosis with and without 22q11 deletion syndrome: a comparison of prodromal psychotic symptoms and general functioning. Schizophr Res. 2012;139:151-6.

63. Schneider M, Van der Linden M, Menghetti S, Glaser B, Debbané M, Eliez S. Predominant negative symptoms in 22q11.2 deletion syndrome and their associations with cognitive functioning and functional outcome. J Psychiatr Res. 2014;48:86-93.

64. Leleu A, Favre E, Yailian A, Fumat H, Klamm J, Amado I, Baudouin JY, Franck $\mathrm{N}$, Demily C. An implicit and reliable neural measure quantifying impaired visual coding of facial expression: evidence from the 22q11.2 deletion syndrome. Transl Psychiatry. 2019;9:67.

65. Frith CD, Corcoran R. Exploring 'theory of mind' in people with schizophrenia. Psychol Med. 1996;26(3):521-30.

66. Corcoran R, Mercer G, Frith CD. Schizophrenia, symptomatology and social inference: investigating "theory of mind" in people with schizophrenia. Schizophr Res. 1995;17(1):5-13.

67. Bliksted V, Videbech $P$, Fagerlund B, Frith $C$. The effect of positive symptoms on social cognition in first-episode schizophrenia is modified 
by the presence of negative symptoms. Neuropsychology. 2017;31(2): 209-19.

68. Garety PA, Kuipers E, Fowler D, Freeman D, Bebbington PE. A cognitive model of the positive symptoms of psychosis. Psychol Med. 2001;31(2):189-95.

69. Schmidt SJ, Mueller DR, Roder V. Social cognition as a mediator variable between neurocognition and functional outcome in schizophrenia: empirical review and new results by structural equation modelling. Schizophr Bull. 2011;37(Suppl. 2):S41-54.

70. Sergi MJ, Rassovsky Y, Nuechterlein $\mathrm{KH}$, et al. Social perception as a mediator of the influence of early visual processing on functional status in schizophrenia. Am J Psychiatry. 2006;163:448-54.

71. Wray E, Shashi V, Schoch K, Curtiss K, Hooper SR. Discrepancies in parent and teacher ratings of social-behavioral functioning of children with chromosome 22q11.2 deletion syndrome: implications for assessment. Am J Intellect Dev Disabil. 2013;118(5):339-52

72. Wagner KE, Kates WR, Fremont W, Antshel KM. Childhood predictors of young adult social functioning in 22q11.2 deletion syndrome. J Autism Dev Disord. 2017;47(8):2480-501.

73. Barch DM. Nonsocial and social cognitive function in psychosis: interrelationships, specificity and innovative approaches. World Psychiatry. 2019:18(2):117-8.

74. Vo OK, McNeill A, Vogt KS. The psychosocial impact of 22q11 deletion syndrome on patients and families: A systematic review. Am J Med Genet. 2018;176(10):2215-25.

75. Fonagy P, Gergely G, Jurist EL, Target M. Affect regulation, mentalization and the development of the self. New York: Other Press; 2002.

76. Glaser B, Lothe A, Chabloz M, Dukes D, Pasca C, Redoute J, Eliez S. Candidate socioemotional remediation program for individuals with intellectual disability. Am J Intellect Dev Disabil. 2012;117(5):368-83.

77. Shashi V, Harrell W, Eack S, Sanders C, McConkie-Rosell A, Keshavan MS, Bonner MJ, Schoch K, Hooper SR. Social cognitive training in adolescents with chromosome 22q11.2 deletion syndrome: feasibility and preliminary effects of the intervention. J Intellect Disabil Res. 2015;59(10):902-13.

78. Roder V, Mueller DR, Brenner HD, Spaulding W. Integrated psychological therapy (IPT) for the treatment of neurocognition, social cognition and social competency in schizophrenia patients. Seattle: Hogrefe \& Huber; 2010.

79. Hogarty GE, Flesher S, Ulrich R, et al. Cognitive enhancement therapy for schizophrenia: effects of a 2-year randomized trial on cognition and behavior. Arch Gen Psychiatry. 2004;61:866-76.

80. Shai D, Belsky J. When words just won't do: introducing parental embodied mentalizing. Child Dev Perspect. 2011;5(3):173-80.

81. Gleeson J, Larsen TK, McGorry P. Psychological treatment in pre- and early psychosis. J Am Acad Psychoanal Dyn Psychiatry. 2003;31(1):229-45.

82. Miller GM, Chapman JP. Misunderstanding analysis of covariance. J Abnormal Psy. 2001;110:40-8.

83. Bryson G, Bell M, Lysaker P. Affect recognition in schizophrenia: a function of global impairment or a specific cognitive deficit. Psychiatry Res. 1997;71: 105-13.

84. Yi JJ, Weinberger R, Moore T, Calkins M, Guri Y, McDonald-McGinn D, Zackai E, Emanuel B, Gur R, Gothelf D, Gur R. Neurocognitive performance on a computerized neurocognitive battery in 22q11. 2 deletion syndrome: a comparison between the US and Israeli cohorts. Brain Cogn. 2016;106:33-41.

85. Benton A, Sivan A, Hamsher K, Varney N, Spreen O. Contribution to neuropsychological assessment. New York: Oxford University Press; 1983.

86. Mondloch CJ, Le Grand R, Maurer D. Configural face processing develops more slowly than featural face processing. Perception. 2002;31(5):553-66.

87. Cambridge cognition. CANTAB Emotion Recognition Task (ERT). 2012. http:// www.cambridgecognition.com.

88. Langdon R, Coltheart M, Ward P. Empathetic perspective-taking is impaired in schizophrenia: evidence from a study of emotion attribution and theory of mind. Cogn Neuropsychiatry. 2006;11:133-55.

89. Ekman P, Friesen W. Measuring facial movement. Environ Psychol Nonverbal Behav. 1976;1:56-75.

90. Nowicki S, Carton J. The measurement of emotional intensity from facial expressions. J Soc Psychol. 1993;133:749-50.

91. Nowicki S, Duke MP. Individual differences in the nonverbal communication of affect: the diagnostic analysis of nonverbal accuracy scale. J Nonverbal Behav. 1994;8:9-35.

92. Bruce V, Campbell RN, Doherty-Sneddon G, Import A, Langton S, McAuley S, et al. Testing face processing skills in children. Br J Dev Psychol. 2000;18: 319-33.
93. Baron-Cohen S, Leslie A, Frith U. Does the autistic child have a "theory of mind"? Cognition. 1985;21(1):37-46.

94. McDonald S, Flanagan S, Rollins J, Kinch J. TASIT: a new clinical tool for assessing social perception after traumatic brain injury. J Head Trauma Rehabil. 2003;18:219-38.

95. Lang PJ, Bradley MM, Cuthbert BN. Technical report A-6, international affective picture system (IAPS): digitized photographs, instruction manual and affective ratings. Gainesville: University of Florida; 2005.

96. Goodman R, Ford T, Simmons H, Gatward R, Meltzer H. Using the strengths and difficulties questionnaire (SDQ) to screen for child psychiatric disorders in a community sample. Br J Psychiatry. 2000;177:534-9.

97. Lord C, Risi S, Lambrecht L, Cook EH, Leventhal BL, DiLavore PC, Rutter M. The autism diagnostic observation schedule-generic: a standard measure of social and communication deficits associated with the spectrum of autism. J Autism Dev Disord. 2000;30(3):205-23.

98. Lord C, Rutter M, Le Couteur A. Autism diagnostic interview-revised: a revised version of a diagnostic interview for caregivers of individuals with possible pervasive developmental disorders. J Autism Dev Disord. 1994; 24(5):659-85.

99. First MB, Spitzer RL, Gibbon M, Williams JBW. Structured clinical interview for DSM-IV Axis I disorders_clinician version (SCID-CV). Washington, DC: American Psychiatric Press; 1997

100. Achenbach TM, Ruffle TM. The child behavior checklist and related forms for assessing behavioral/emotional problems and competencies. Pediatr Rev. 2000;21.

101. Shaffer D, Fisher $P$, Lucas $C$. The computerized diagnostic interview schedule for children (C-DISC). Comprehensive handbook of psychological assessment, Vol. 2. Personality assessment. Edited by Hilsenroth MJ, Segal DL. NJ: Wiley; 2004.

102. Hall RC. Global assessment of functioning: a modified scale. Psychosomatics. 1995;36:267-75

103. Kaufman J, Birmaher B, Brent D, et al. Schedule for affective disorders and schizophrenia for school-age children-present and lifetime version (K-SADSPL): initial reliability and validity data. J Am Acad Child Adolesc Psychiatry. 1997:36:980-8

104. McGlashan T, Miller T, Woods S, Rosen J, Hoffman R, Davidson L. Structured interview for prodromal syndromes. New Haven: Prime Clinic Yae School of Medicine; 2003. Version 4

105. Achenbach TM, Rescorla LA. Manual for the ASEBA school-age forms and profiles. Burlington: University of Vermont, Research Center for Children, Youth, and Families; 2001

106. Achenbach TM, Rescorla LA. Manual for the ASEBA adult forms and profiles. Burlington: University of Vermont, Research Center for Children, Youth, and Families; 2003

107. Reich W. Diagnostic interview for children and adolescents (DICA). J Am Acad Child Adolesc Psychiatry. 2000;39:59-66.

108. Constantino J. The social responsiveness scale. Los Angeles: Western Psychological Services; 2002.

109. Gresham FM, Elliot SN. Social skills rating system. Circle Pines: American Guidance Service, Inc:; 1990.

110. Harrison P, Oakland T. Adaptive behavior assessment system-second edition (ABAS-II). San Antonio: The Psychological Corporation; 2003.

111. Sparrow SS, Balla DA, Cicchetti DV. Vineland adaptive behaviour scales. Circle Pines: American Guidance Service; 1984.

112. Bouvard M, Cottraux J, Charles S, Ciadella P, Guerin J, Aimard G. Validation of a French version of Weissman \& Beck's dysfunctional attitude scale (DAS form A). Thér Comportementale Cogn. 1994;4:127-35.

113. Reynolds C, Kamphaus R. Reynolds intellectual assessment scales and Reynolds intellectual screening test professional manual (Danish version). Lutz: Psychological Assessment Resources; 2003.

114. Wechsler D. Wechsler adult intelligence scale: third edition. Administration and scoring manual. San Antonio: Psychological Corporation; 1997.

115. Wechsler D. Intelligence scale for children: fourth edition. San Antonio: The Psychological Corporation; 2003.

116. Bishop DVM. The test for reception of grammar (TROG), Published by the author and available from Age and Cognitive Performance Research Centre, University of Manchester, M13 9PL, UK. 2nd ed; 1983.

117. Phillips LH, Wynn VE, McPherson S, Gilhooly KJ. Mental planning and the tower of London task. Q J Exp Psychol. 2001;54:579-97.

118. Kern RS, Green MF, Nuechterlein KH, Deng BH. NIMH-MATRICS survey on assessment of neurocognition in schizophrenia. Schizophr Res. 2004;72:11-9. 
119. Chelune GJ, Baer RA. Developmental norms for the Wisconsin card sorting test. J Clin Exp Neuropsychol. 1986;8:219-28.

120. Delis DC, Kramer JH, Kaplan E, Ober BA. California verbal learning test-children's version (CVLTC). San Antonio: The Psychological Corporation; 1993.

121. Cornblatt BA, Risch NJ, Faris G, Friedman D, Erlenmeyer-Kimling L. The continuous performance test, identical pairs version (CPT-IP): I. new findings about sustained attention in normal families. Psychiatry Res. 1988;26:223-38.

\section{Publisher's Note}

Springer Nature remains neutral with regard to jurisdictional claims in published maps and institutional affiliations.

Ready to submit your research? Choose BMC and benefit from:

- fast, convenient online submission

- thorough peer review by experienced researchers in your field

- rapid publication on acceptance

- support for research data, including large and complex data types

- gold Open Access which fosters wider collaboration and increased citations

- maximum visibility for your research: over $100 \mathrm{M}$ website views per year

At $\mathrm{BMC}$, research is always in progress.

Learn more biomedcentral.com/submissions 